\title{
Internal Mammary Artery Perforator Flap for Immediate Volume Replacement Following Wide Local Excision of Breast Cancer
}

\author{
Martine A. van Huizum ${ }^{1}$, J. Joris Hage ${ }^{1}$, Hester A. Oldenburg ${ }^{2}$, Marije J. Hoornweg ${ }^{1}$ \\ Departments of ${ }^{1}$ Plastic and Reconstructive Surgery and ${ }^{2}$ Surgical Oncology, the Netherlands Cancer Institute-Antoni van Leeuwenhoek \\ Hospital, Amsterdam, The Netherlands
}

Background Breast-conserving therapy is defined as a breast-conserving wide local excision (WLE) of a mammary tumour combined with postoperative radiotherapy. Immediate restoration of the mammary shape by use of breast reduction techniques (volume displacement) or tissue replacement techniques (volume replacement) is gaining popularity to prevent breast malformation.

Methods To date, using the internal mammary artery perforator (IMAP) flap has been suggested for immediate volume replacement after WLE, but has never been evaluated in a published study.

Results We applied this flap in 12 women (mean age, 56.1 years) after WLE (mean specimen weight, $46.5 \mathrm{~g}$ ) of the medial aspect of the breast. Over a median follow-up of 35.3 months (standard deviation, 1.2 months), 4 women needed repeated surgery for dog-ear correction of the donor site.

Conclusions In our experience, the use of an IMAP flap was a reliable technique with good cosmetic outcomes after oncoplastic reconstruction. In this series, donor site revision often proved necessary initially, but we showed that this may easily be prevented.

Keywords Breast neoplasms / Perforator flap / Mammaplasty / Mastectomy, segmental

Received: 4 Apr 2016• Revised: 26 Jun 2017 • Accepted: 2 Aug 2017

pISSN: 2234-6163 • elSSN: 2234-6171 • https://doi.org/10.5999/aps.2016.00458• Arch Plast Surg 2017;44:502-508
Correspondence: Marije J. Hoornweg Department of Plastic and Reconstructive Surgery, Netherlands Cancer Institute-Antoni van Leeuwenhoek Hospital, NL-1066 CX Amsterdam, The Netherlands Tel: +31-20-512-7417 Fax: +31-20-512-2554 E-mail:m.hoornweg@nki.nl

\section{INTRODUCTION}

Breast-conserving therapy (BCT) is defined as a breast-conserving wide local excision (WLE) of a mammary tumour combined with postoperative radiotherapy $[1,2]$. The overall survival rate of $\mathrm{BCT}$ is equivalent to that of mastectomy for women with early-stage breast cancer [2,3], while preservation of the remaining breast is associated with better psychosocial and psychosexual rehabilitation [4]. Still, BCT is associated with a risk of malformation of the breast, particularly in cases where more than $20 \%$ of the mammary volume is excised [5]. The medial quadrants of the breast are especially prone to such a malformation $[1,6]$.

Immediate restoration of the mammary shape by using breast reduction techniques (volume displacement) and immediate restoration of mammary volume by using tissue replacement techniques (volume replacement) are gaining popularity to prevent such malformations [7-9]. Tissue replacement techniques may, furthermore, prevent the need for symmetrizing contralateral reduction mammoplasty. 
We currently utilize an internal mammary artery perforator (IMAP) flap for immediate tissue replacement after WLE in the medial half of the breast. Because the immediate use of the IMAP flap has not been evaluated in a published study, we present our initial experience with its feasibility, preoperative planning, intraoperative details, and pitfalls, and evaluate the surgical and cosmetic outcomes of this technique.

\section{METHODS}

\section{Patients}

From January 2011 through January 2015, 256 oncoplastic WLEs were performed in 249 women with ductal carcinoma in situ $(\mathrm{n}=56)$, invasive ductal carcinoma $(\mathrm{n}=180)$, or benign tumours $(n=13)$. Breast reduction techniques were applied in 172 of these 249 women, whereas an immediate tissue replacement technique was used in the remaining 77 women. Two women underwent bilateral operations, and 5 others underwent repeated WLE and tissue displacement after an initial non-radical WLE combined with tissue displacement. We used the IMAP flap to replace a mean weight of $46.5 \mathrm{~g}$ (median, $36.0 \mathrm{~g}$; standard deviation [SD], $30.1 \mathrm{~g}$ ) of excised medial breast tissue in 12 non-smoking women with a mean age of 56.1 years (median, 55.7 years; SD, 6.2 years) and a mean body mass index of $24.5 \mathrm{~kg} / \mathrm{m}^{2}$ (median, $23.2 \mathrm{~kg} / \mathrm{m}^{2}$; SD, $3.9 \mathrm{~kg} / \mathrm{m}^{2}$ ) (Table 1).

\section{Preoperative planning}

Preoperative perforator mapping was performed with a unidi- rectional Doppler probe $(8 \mathrm{~Hz})$ with the patient in the supine position. The perforator of the fourth or fifth ipsilateral intercostal space was marked on the skin, approximately 6 to $11 \mathrm{~mm}$ lateral to the sternal border [10]. The superior border of the flap was projected in the inframammary fold to assure that the flap would contain abdominal, rather than mammary tissue (Figs. 1,2). The width and inferior border of the skin pedicle flap were established by pinching the inframammary skin and subcutis between the thumb and index finger. The length of the flap could reach the anterior axillary fold, but was preoperatively designed and intraoperatively adjusted depending on the replacement volume needed [11].

\section{Surgical technique}

The women underwent surgery in the supine position with both arms abducted at $90^{\circ}$. Immediately following the WLE and possible axillary node dissection, the skin was incised as planned. The flap was raised from its lateral edge overlying the external oblique muscle towards the rectus fascia, thus approaching the IMAP. Medially, we preserved a skin pedicle in the first 6 women. Propeller flaps were applied in the latter 6 women. Subsequently, the abdominal, caudal edge of the donor flap was raised at a suprafascial level. This edge was then advanced cranially over a vacuum drain towards the inframammary fold using ample subcutaneous quilting sutures. After the lower incision line was situated in the inframammary fold in this way, we fixed it to the fascia with vicryl 2-0 sutures to prevent caudal displacement of the inframammary fold.

\section{Table 1. Characteristics of 12 women who underwent wide local excision and oncoplastic reconstruction using an IMAP flap}

\begin{tabular}{|c|c|c|c|c|c|c|c|c|c|c|c|c|}
\hline \multirow{2}{*}{ Characteristic } & \multicolumn{12}{|c|}{ Patient number } \\
\hline & 1 & 2 & 3 & 4 & 5 & 6 & 7 & 8 & 9 & 10 & 11 & 12 \\
\hline Age (yr) & 55.5 & 56.0 & 61.6 & 50.6 & 55.0 & 57.8 & 58.4 & 59.6 & 48.6 & 51.8 & 70.0 & 47.7 \\
\hline $\mathrm{BMl}\left(\mathrm{kg} / \mathrm{m}^{2}\right)$ & 26.5 & 30.1 & 33.5 & 25.5 & 22.5 & 21.8 & 21.2 & 21.6 & 23.1 & 19.6 & 25.0 & 23.3 \\
\hline Site & $\mathrm{R}$ & L & $\mathrm{R}$ & $\mathrm{R}$ & $\mathrm{R}$ & $\mathrm{R}$ & $\mathrm{R}$ & L & $\mathrm{R}$ & $\mathrm{R}$ & L & $\mathrm{R}$ \\
\hline TNM class & T1N1 & T1NO & T1N0 & T2NO & T1N3 & DCIS & T1N0 & T1N0 & T1N0 & DCIS & T1NO & Phyllodes \\
\hline Weight of WLE (g) & 26 & 67 & 125 & 54 & 33 & 22 & 47 & 39 & 28 & 18 & 71 & 28 \\
\hline NAC & + & - & - & + & + & - & - & - & - & - & - & - \\
\hline Pathology & $\begin{array}{l}\text { IDC } \\
\mathrm{rad}\end{array}$ & $\begin{array}{l}\mathrm{IDC} \\
\mathrm{rad}\end{array}$ & $\begin{array}{l}\text { IDC } \\
\mathrm{rad}\end{array}$ & $\begin{array}{l}\text { ILC } \\
\text { irr }\end{array}$ & $\begin{array}{l}\text { IDC } \\
\text { irr }\end{array}$ & $\begin{array}{c}\text { DCIS } \\
\text { rad }\end{array}$ & $\begin{array}{c}\text { IDC/DCIS } \\
\text { irr }\end{array}$ & $\begin{array}{l}\text { IDC } \\
\mathrm{rad}\end{array}$ & $\begin{array}{c}\text { IDC/DCIS } \\
\text { irr }\end{array}$ & $\begin{array}{l}\text { DCIS } \\
\text { irr }\end{array}$ & $\begin{array}{l}\text { DCIS } \\
\text { irr }\end{array}$ & Phyllodes \\
\hline Adjuvant RTh & + & + & + & + & + & + & - & + & + & - & + & - \\
\hline Adjuvant HTh & + & - & - & - & + & - & - & - & - & - & - & - \\
\hline Adjuvant Cth & - & - & - & - & - & - & + & + & + & - & - & - \\
\hline Lipofilling & - & - & + & - & - & + & - & - & + & - & - & - \\
\hline Dog ear & - & + & - & - & + & - & - & - & + & - & - & - \\
\hline Re-excision & - & - & - & - & - & - & + & - & - & - & - & - \\
\hline Breast cosmesis & 8 & 8 & 7 & 6 & 7 & 7 & 8 & 9 & 8 & 9 & 10 & $\mathrm{mv}$ \\
\hline Nipple cosmesis & $\mathrm{mv}$ & 10 & 10 & 7 & 10 & 10 & 7 & 9 & 10 & 10 & 10 & $\mathrm{mv}$ \\
\hline
\end{tabular}




\section{Fig. 1. Preoperative design of the IMAP flap}

The design was made with the patient in supine position. $X$ indicates the location of the tumour. IMAP, internal mammary artery perforator.

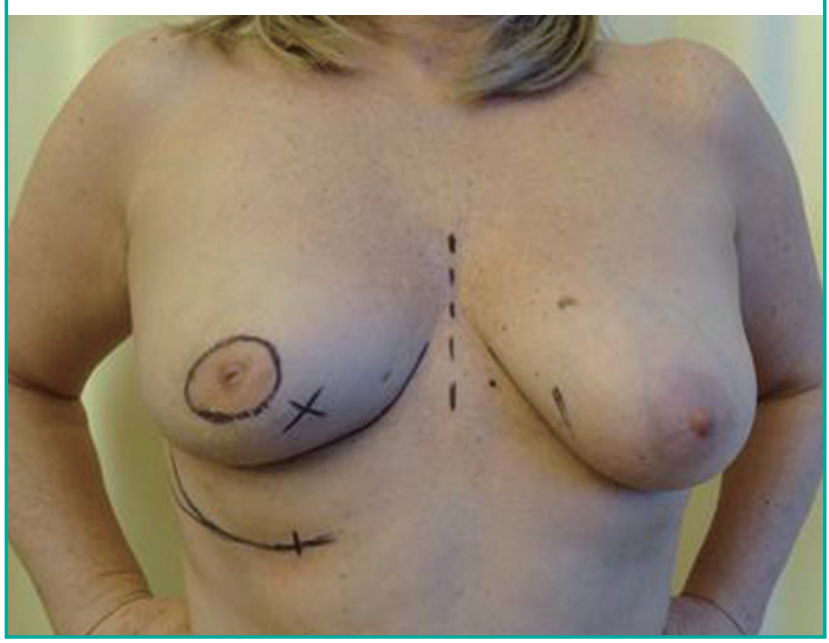

\section{Fig. 2. Design of the IMAP flap after WLE}

The small o indicates the IMAP. The large 0 indicates the WLE defect. IMAP, internal mammary artery perforator; WLE, wide local excision.

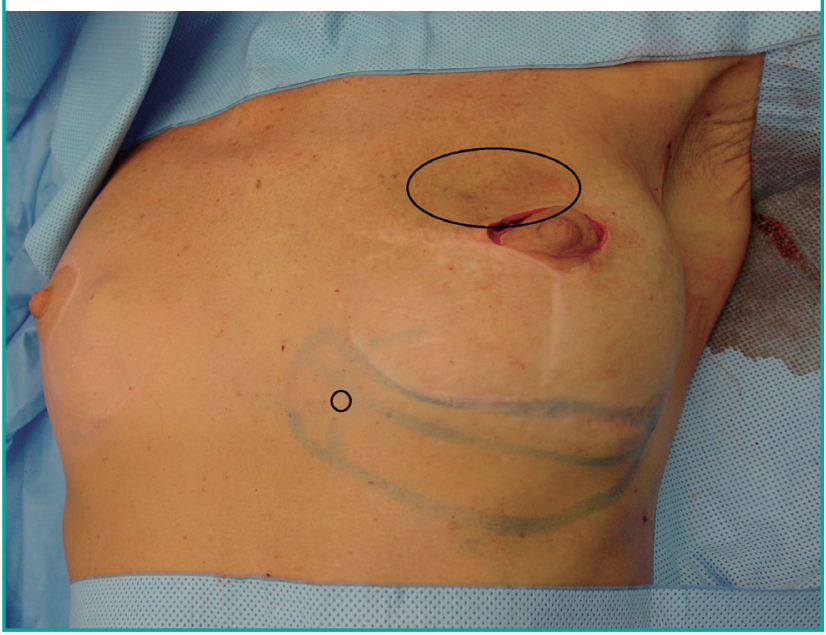

\section{Fig. 3. Rotation and tunneling}

The de-epithelialized IMAP flap was rotated and tunnelled from the inframammary fold into the medial mammary defect. IMAP, internal mammary artery perforator.

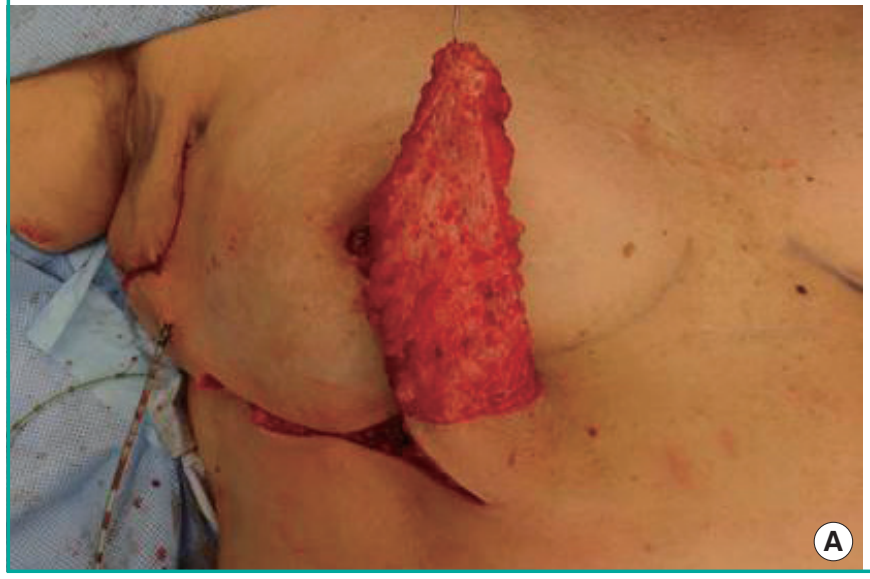

The flap was rotated $90^{\circ}$ and tunnelled from the inframammary fold into the medial mammary defect. The IMAP flap was de-epithelialized as needed and fixed in the recipient site with vicryl 3-0 sutures in order to prevent dead space (Figs. 3, 4). Finally, the skin was closed intracutaneously (Figs. 5, 6).

The women were discharged from hospital on the first day after surgery. The drain was left until its production was less than $20 \mathrm{~mL} / 24$ hour. Three weeks postoperatively, all patients were seen at our outpatient clinic to evaluate the healing of the breast in order to treat possible complications before adjuvant radiotherapy was started 4 weeks postoperatively.

\section{Follow up and cosmetic evaluation}

Further postoperative assessments were performed routinely at

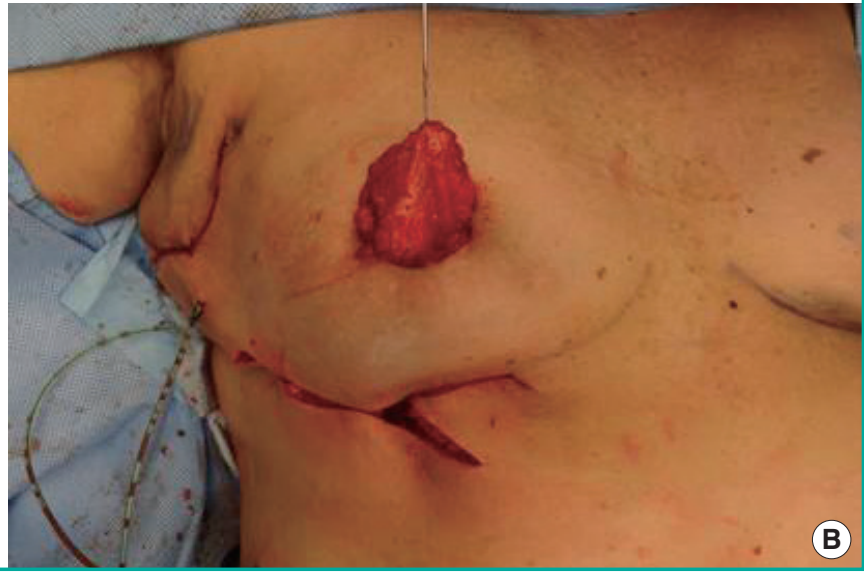

3 and 6 months after surgery (Fig. 7). Any additional conservative or surgical treatment was noted. All women evaluated the cosmetic outcome and position of the nipple on a scale from 0 (very unsatisfactory) to 10 (very satisfactory), after a median follow-up of 35 months (SD, 1.2 months). They were asked about volume asymmetry compared to the non-operated contralateral breast and about possible pain in the reconstructed breast or donor area. Last, they indicated whether they would choose the oncoplastic approach with an IMAP flap reconstruction again in a similar situation.

\section{RESULTS}

We observed no wound dehiscence, infection, (partial) flap loss, 


\section{Fig. 4. Rotation and tunneling}

Rotation and tunnelling of the de-epithelialized propeller IMAP flap. The de-epithelialized propeller IMAP flap was rotated and tunnelled from the inframammary fold into the mediocranial mammary defect. IMAP, internal mammary artery perforator.
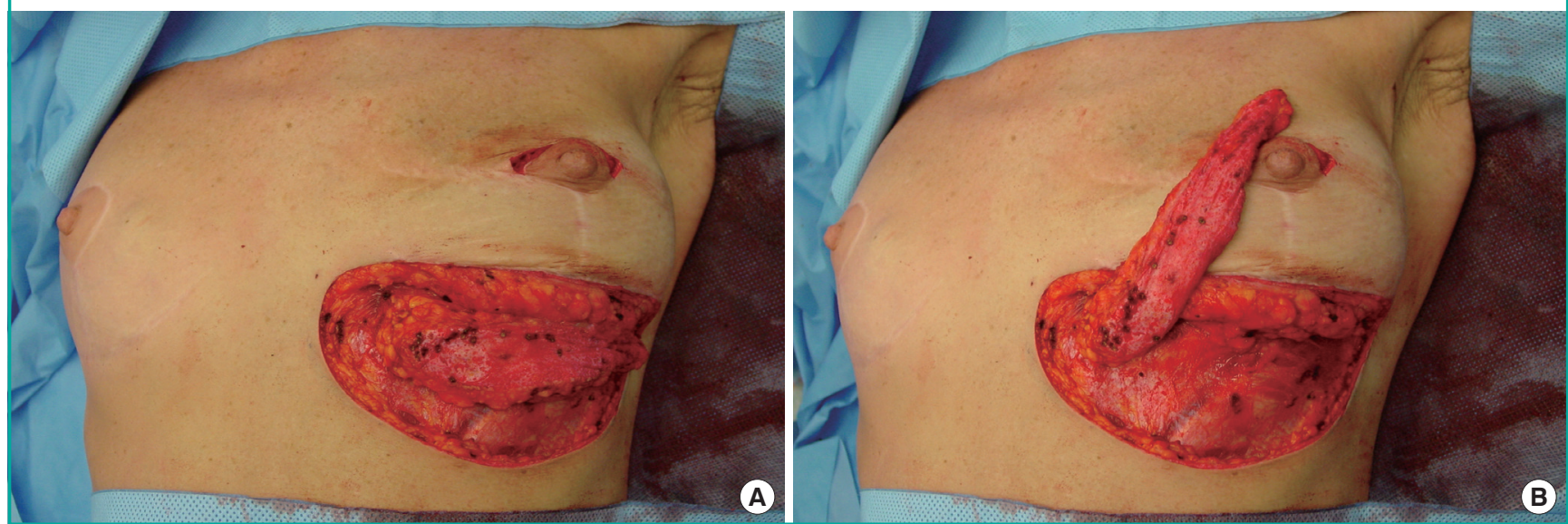

\section{Fig. 5. Result immediate postoperative}

The donor site after intracutaneous closure of the skin.

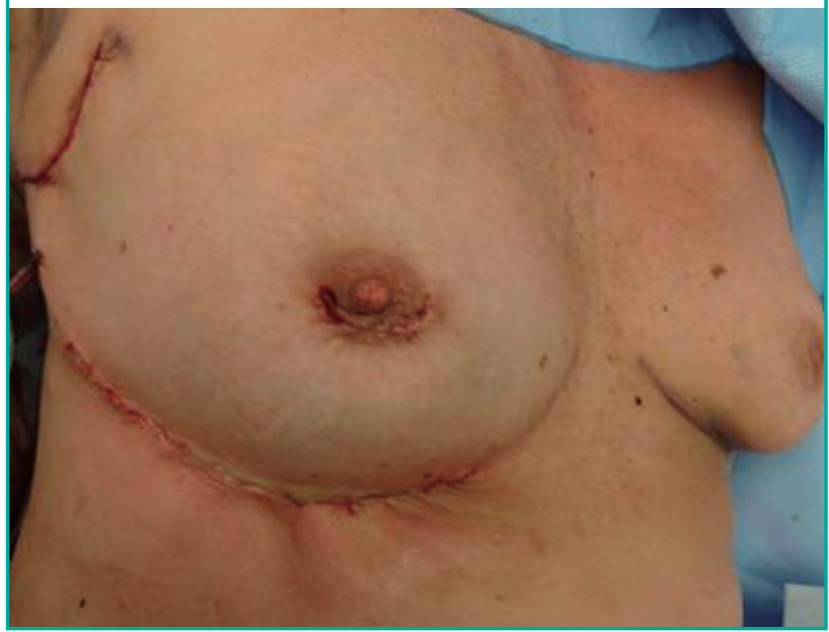

or fat necrosis in this series. Consequently, adjuvant radiation treatment did not need to be delayed in any of the women. Because of the non-radical resection of the tumour in 2 of the women, additional radiation therapy was applied in one and a skin-sparing mastectomy in the other. This mastectomy was combined with reconstruction by immediate use of a subpectorally implanted endoprothesis. It was not hampered by the prior tissue replacement approach.

Complementary cosmetic correction of the donor area was performed at the request of 5 of the 12 women (Table 1 ), at a mean of 18.8 months after the primary operation (range, 9-37 months). In all 5 of these women, a pedicled flap rather than a propeller flap had been used primarily. Three of these women underwent adhesiolysis and lipofilling of the donor scar. In 1 of these 3 women, this was combined with lipofilling of the recep-

\section{Fig. 6. Result immediate postoperative}

The donor site after intracutaneous closure of the skin.

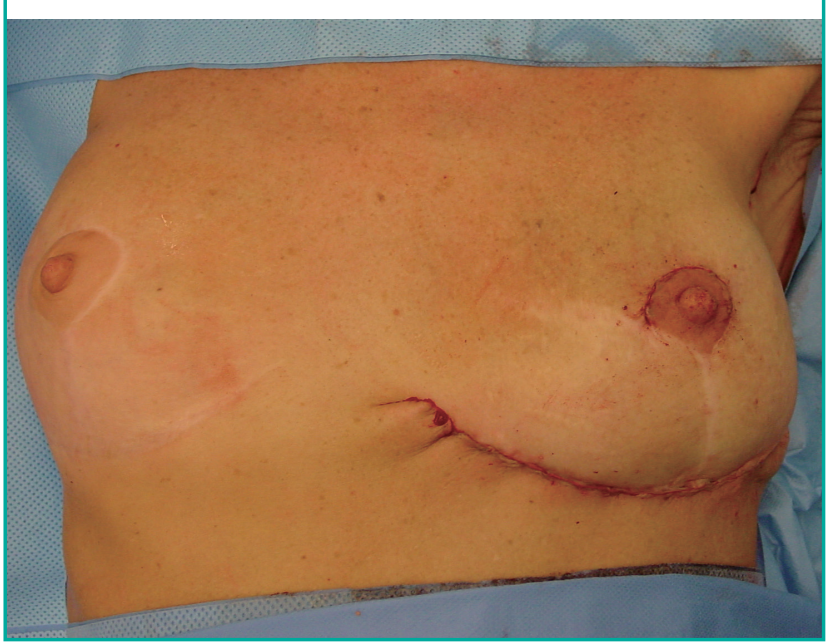

Fig. 7. Result at 6 months after surgery

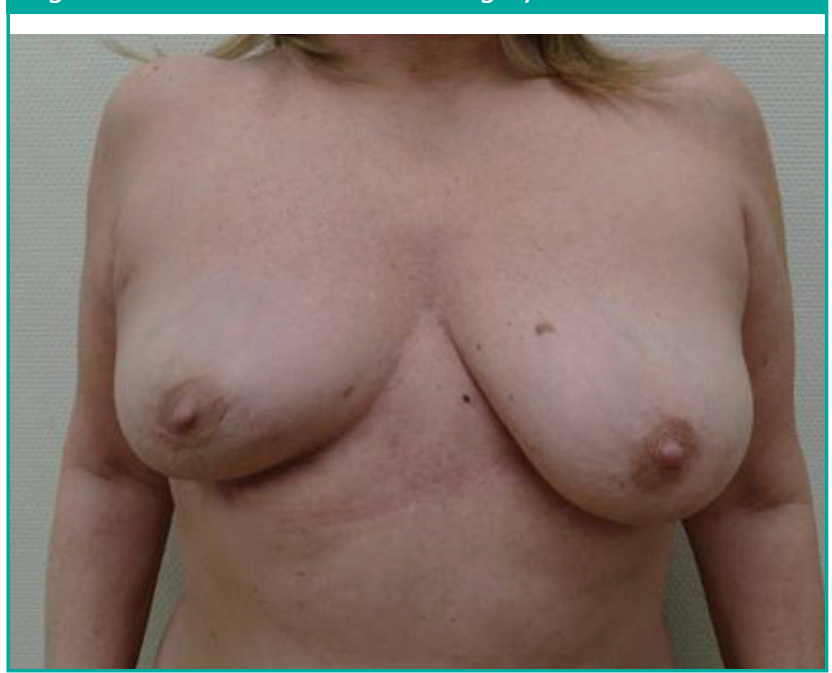


tor area for a minor deficit of the mammary contour. Correction of a dog-ear deformity at the base of the skin pedicle of the flap was performed under local anaesthesia in the 2 other women, early in the series.

The cosmetic outcome received a mean score of 7.9 out of 10 and the position of the nipple received a mean score of 9.3 out of 10 . Two women experienced minimal volume asymmetry in comparison with the contralateral breast and occasional pain located at the donor site. None of the women needed symmetrizing contralateral reduction mammoplasty. All the women would choose the IMAP flap technique again in a similar situation.

\section{DISCUSSION}

\section{General advantages and disadvantages of oncoplastic reconstruction after WLE}

The ultimate goal of oncoplastic WLE is to allow relatively largevolume resections with free margins and fewer re-excisions and additional mastectomies than can be obtained with standard WLE [12]. It allows restoration of breast shape and volume before radiation therapy is started. This results in more patients being satisfied with the cosmetic outcome $[12,13]$. Consequently, it may prevent secondary, post-radiotherapy surgical correction of mammary malformations $[1,14]$. Although this combined oncoplastic approach has extended the indications for BCT, its true value for the prevention of local recurrence remains to be determined [12]. Although many guidelines and extensions of indications have been suggested [1,15-17], there are no standardized practices or guidelines regarding the use of oncoplastic reconstruction [18].

A disadvantage of volume replacement techniques may be donor site morbidity and flap failure [7]. Furthermore, oncological re-operations may be more difficult in cases where the initial excision turns out to have been pathologically non-radical [12].

\section{Development of the IMAP flap}

Starting in 1917, IMAP-based flaps have been used, mostly for head and neck reconstruction [19]. The ability of the lower perforating branches of the internal mammary vessels to serve as the vascular pedicle of a true island flap was proven by Kalender et al. [20] when they introduced the use of the IMAP flap for post-burn mammary correction in 2000. Subsequently, the use of this flap was described for secondary contralateral breast reconstruction [20-22] and the reconstruction of anterior chest wall defects following ablative surgery $[23,24]$. During preoperative planning, it is not always clear whether the most inferior IMAP or the most superior epigastric artery perforator (SEAP) is included in the flap. Although the potential use of the IMAP or SEAP flap $[23,25]$ for immediate ipsilateral oncoplastic breast reconstruction has been suggested, no reports on this use have been published so far.

\section{Potential limitations of our methodology}

Before we discuss the clinical implications of our observations, some potential limitations of our report need be addressed. The small number of patients may be explained by the limited incidence of tumours in the medial quadrants of the breast. Still, our mean follow-up of 2.6 years indicates that the use of the IMAP flap for this indication is not just feasible, but successful as well.

A second limitation may be that the successful use of this flap depends on cooperation between an oncological surgeon and a reconstructive surgeon and on both their personal experiences [1]. Hence, our experience may not be easily extrapolated to other clinics, despite the generally increasing interest in oncoplastic techniques.

\section{Clinical implications of our observations}

In this series, we replaced the resected tissue of oncologic specimens of a maximum of $125 \mathrm{~g}$ (range, 18-125 g; SD, $30.1 \mathrm{~g}$ ) (Table 1). This, however, did not constitute the maximum possible weight of the IMAP, which obviously depends on the body mass index and superior abdominal skin laxity of the patient. In cases where this maximum volume proves insufficient to replace all tissue loss, immediate or secondary additional lipofilling may be performed. Furthermore, the perforator itself may be dissected in cases where additional advancement of the flap is needed, although this did not occur in our series [19].

We observed no flap loss and the overall satisfaction of our patients was good. Adhesiolysis of the scar and dog-ear correction at the donor site were the main reasons for re-operation. To prevent dog-ear corrections in the latter half of this series, we incised the skin pedicle of the flaps and applied the flaps as true propeller flaps in patients number 7 through number 12 (Table 1 ). Although the mean breast cosmesis scores among these latter 6 patients (mean, 8.67; SD, 0.58) were more favourable than those among the 6 patients in whom a pedicled flap was applied (mean, 7.63; SD, 1.19), this difference did not reach statistical significance $(\mathrm{P}=0.36)$. We advise the liberal application of quilting sutures when advancing the abdominal edge of the donor site towards the inframammary fold in order to reduce possible traction on this fold and the donor scar.

In conclusion, we chose to use the IMAP flap for medial breast defects because it is a reliable fasciocutaneous local flap with good cosmetic outcomes. The favourable results of using the IMAP flap in breast-conserving surgery widen the applications of this flap, which may lead to a further increase of indications 
for breast-conserving surgery. Although donor site revision often proved necessary in the first half of this series, we showed this to be easily preventable in the latter half.

\section{CONFLICT OF INTEREST}

No potential conflict of interest relevant to this article was reported.

\section{PATIENT CONSENT}

The patient provided written informed consent for the publication and the use of their images.

\section{REFERENCES}

1. Clough KB, Kaufman GJ, Nos C, et al. Improving breast cancer surgery: a classification and quadrant per quadrant atlas for oncoplastic surgery. Ann Surg Oncol 2010;17:137591.

2. Veronesi U, Cascinelli N, Mariani L, et al. Twenty-year follow-up of a randomized study comparing breast-conserving surgery with radical mastectomy for early breast cancer. N Engl J Med 2002;347:1227-32.

3. Litiere S, Werutsky G, Fentiman IS, et al. Breast conserving therapy versus mastectomy for stage I-II breast cancer: 20 year follow-up of the EORTC 10801 phase 3 randomised trial. Lancet Oncol 2012;13:412-9.

4. Al-Ghazal SK, Fallowfield L, Blamey RW. Comparison of psychological aspects and patient satisfaction following breast conserving surgery, simple mastectomy and breast reconstruction. Eur J Cancer 2000;36:1938-43.

5. Bulstrode NW, Shrotria S. Prediction of cosmetic outcome following conservative breast surgery using breast volume measurements. Breast 2001;10:124-6.

6. Rainsbury RM. Surgery insight: Oncoplastic breast-conserving reconstruction: indications, benefits, choices and outcomes. Nat Clin Pract Oncol 2007;4:657-64.

7. Yang JD, Lee JW, Cho YK, et al. Surgical techniques for personalized oncoplastic surgery in breast cancer patients with small- to moderate-sized breasts (part 1): volume displacement. J Breast Cancer 2012;15:1-6.

8. Losken A, Zenn MR, Hammel JA, et al. Assessment of zonal perfusion using intraoperative angiography during abdominal flap breast reconstruction. Plast Reconstr Surg 2012;129: 618e-624e.

9. Yang JD, Lee JW, Cho YK, et al. Surgical techniques for personalized oncoplastic surgery in breast cancer patients with small- to moderate-sized breasts (part 2): volume replacement. J Breast Cancer 2012;15:7-14.

10. Gillis JA, Prasad V, Morris SF. Three-dimensional analysis of the internal mammary artery perforator flap. Plast Reconstr Surg 2011;128:419e-426e.

11. Schmidt M, Aszmann OC, Beck H, et al. The anatomic basis of the internal mammary artery perforator flap: a cadaver study. J Plast Reconstr Aesthet Surg 2010;63:191-6.

12. Losken A, Dugal CS, Styblo TM, et al. A meta-analysis comparing breast conservation therapy alone to the oncoplastic technique. Ann Plast Surg 2014;72:145-9.

13. Veiga DF, Veiga-Filho J, Ribeiro LM, et al. Quality-of-life and self-esteem outcomes after oncoplastic breast-conserving surgery. Plast Reconstr Surg 2010;125:811-7.

14. Dewar JA, Benhamou S, Benhamou E, et al. Cosmetic results following lumpectomy, axillary dissection and radiotherapy for small breast cancers. Radiother Oncol 1988;12: 273-80.

15. Kronowitz SJ, Hunt KK, Kuerer HM, et al. Practical guidelines for repair of partial mastectomy defects using the breast reduction technique in patients undergoing breast conservation therapy. Plast Reconstr Surg 2007;120:1755-68.

16. Kronowitz SJ, Kuerer HM, Buchholz TA, et al. A management algorithm and practical oncoplastic surgical techniques for repairing partial mastectomy defects. Plast Reconstr Surg 2008;122:1631-47.

17. Hamdi M, Sinove Y, DePypere H, et al. The role of oncoplastic surgery in breast cancer. Acta Chir Belg 2008;108: 666-72.

18. Clough KB, Benyahi D, Nos C, et al. Oncoplastic surgery: pushing the limits of breast-conserving surgery. Breast $\mathrm{J}$ 2015;21:140-6.

19. Schellekens PP, Paes EC, Hage JJ, et al. Anatomy of the vascular pedicle of the internal mammary artery perforator (IMAP) flap as applied for head and neck reconstruction. J Plast Reconstr Aesthet Surg 2011;64:53-7.

20. Kalender V, Aydm H, Karabulut AB, et al. Breast reconstruction with the internal mammary artery pedicled fasciocutaneous island flap: description of a new flap. Plast Reconstr Surg 2000;106:1494-8.

21. Schoeller T, Bauer T, Haug M, et al. A new contralateral split-breast flap for breast reconstruction and its salvage after complication: an alternative for select patients. Ann Plast Surg 2001;47:442-5.

22. Schwabegger AH, Piza-Katzer H, Pauzenberger R, et al. The internal mammary artery perforator (IMAP) breast-flap harvested from an asymmetric hyperplastic breast for correction of a mild funnel chest deformity. Aesthetic Plast 
Surg 2011;35:928-32.

23. Hamdi M, Van Landuyt K, Ulens S, et al. Clinical applications of the superior epigastric artery perforator (SEAP) flap: anatomical studies and preoperative perforator mapping with multidetector CT. J Plast Reconstr Aesthet Surg 2009;62:1127-34.
24. Karabulut AB, Kalender V. Internal mammary artery pedicled island flap for the treatment of chest wall radionecrosis. Plast Reconstr Surg 2001;108:583-4.

25. Blondeel PN, Van Landuyt KH, Monstrey SJ, et al. The "Gent" consensus on perforator flap terminology: preliminary definitions. Plast Reconstr Surg 2003;112:1378-83. 